Departamento de Patologia e Clínica Médicas (2. ${ }^{\mathrm{a}}$ cadeira) Diretor: Prof. contratado Dr. Romeu Diniz Lamounier

\title{
SÖBRE UM CASO DE NECROBACILOSE BOVINA EM SÃO PAULO, ORIUNDO DE UM POSSÍVEL FOCO
}

\author{
Romeu D. Lamounier e Paulo de Carvalho Pereira \\ Assistente \\ 3 estampas (5 figuras)
}

Um de nós já teve oportunidade de cooperar em outro trabalho (1) para assinalar a necrobacilose em Minas Gerais e agora tivemos um caso em São Paulo, se não idêntico, pelo menos muito semelhante.

Chamamos a atenção para êstes casos, por nós agora e anteriormente (1) designados de necrobacilose, freqüentes em Minas Gerais e pelas informações colhidas, em São Paulo onde ha focos que necessitam estudo para estabelecer um ponto que consideramos de máxima importância, ou seja, saber se o Actinomyces necrophorus é a causa primária ou simplesmente um agente secundário; porque esta bactéria é comumente encontrada como saprófita no tubo digestivo de várias espécies animais (2) e assim poderá, em determinados processos, ser simplesmente um invasor secundário.

Não conhecemos em São Paulo trabalho algum que assinale as lesões por nós estudadas em bezerro, das quais isolamos o Actinomyces necrophorus sendo, provàvelmente, a primeira vez assinaladas em São Paulo.

Em junho de 1945 tendo sido enviado, pelo professor João Soares Veiga, à cadeira de Patologia e Clínica Médicas (2. ${ }^{\mathrm{a}}$ cadeira), um bezerro proveniente de Guaratinguetá, Estado de São Paulo, nosso exame revelou o seguinte:

a) - IdENTIFICAÇÃo Do ANIMAL: espécie bovina, mestiço, com a idade aproximadamente de 5 meses, procedente de Guaratinguetá, Estado de São Paulo.

b) - ANAMnESE: pela anamnese soubemos, além da história do caso atual, da existência de outros animais com as mesmas lesões, tanto na propriedade do criador a quem pertence o animal por nós examinado, como em outras propriedades da mesma zona, sendo que em anos anteriores o referido criador teve maior número de animais doentes.

Tratando-se de uma doença infeciosa e havendo grande número de animais atacados, julgamos ter motivos suficientes para considerar possível a existência de um foco de necrobacilose naquela zona. 
c) - Exame clínico geral: pulso forte, rítmico e com a freqüência de 96 pulsações por minuto.

Respiração: 15 movimentos respiratórios por minuto.

Temperatura retal: $39,5^{\circ} \mathrm{C}$.

Mucosas oculares: congestionadas.

CABEÇA - lado esquerdo: revelava, na região da apófise zigomática, uma bossa muito saliente, com cêrca de $8 \mathrm{~cm}$ (fig. 1) de diâmetro; os gânglios pré-parotidiano, retro-faringiano e sub-maxilar do mesmo lado estavam hipertrofiados.

Lado direito: à exceção de um ligeiro aumento da apófise zigomática, nada mais foi notado de anormal, assim como no espaço inter-maxilar.

Ainda pela inspeção notamos descolamento do casco anterior direito. (fig. 2).

BocA: cheiro fétido, molares e pré-molares superiores esquerdos ausentes, exceto o $3 .^{\circ}$ molar; no ponto correspondente aos dentes citados, lesões extensas com a formação de pseudo-membranas, e, mais profundamente, a parte óssea corroída se destacava fàcilmente deixando uma superficie lisa em comunicação com a cavidade nasal, por intermédio do seio maxilar esquerdo. Do lado direito havia simplesmente congestão e tumefação da gengiva na região dos dentes prémolares e molares.

EXAME DOS APARELHOS: nada mostrou de anormal.

d) - EXAmes de laboratório

1) - QUADRo HEMATológico: o quadro hematológico encontrado foi o seguinte:

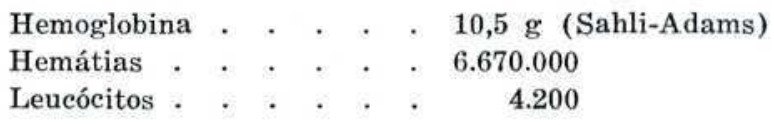

CONTAGEM ESPECfFICA:

\begin{tabular}{|c|c|c|c|c|c|c|c|c|c|c|c|c|}
\hline \multirow{7}{*}{ Neutrófilos } & \multirow{2}{*}{\multicolumn{2}{|c|}{ Metamielocitos }} & . & . & . & . & • & \multicolumn{2}{|c|}{. . } & & . & . $\quad 0 \%$ \\
\hline & & & . & . & . & . & . & . & . & . & . & . $1 \%$ \\
\hline & Segmentados & & . & . & . & . & . & . & . & . & . & $14 \%$ \\
\hline & Eosinófilos & . & . & . & . & . & . & . & . & . & . & $0 \%$ \\
\hline & Basófilos & . & . & . & . & . & . & . & . & . & . & $0 \%$ \\
\hline & Monócitos & . & . & . & . & . & . & . & . & . & . & $1 \%$ \\
\hline & Linfócitos & . & . & . & . & . & . & . & . & . & . & $84 \%$ \\
\hline
\end{tabular}

2) SôRO-AGLUTINAÇÃo RÁPIDA PARA BRUCELOSE: negativa.

3) EXAME DE FEZES: regular quantidade de ovos de Strongyloidéa. 
4) EXAME DE URINA (colhida acidentalmente em micção espontânea) : nada revelou de anormal.

5) EXAME BACTERIoLógico: com material colhido dos fragmentos ósseos retirados do foco, fizemos esfregaços que revelaram, além de outras formas bacterianas, uma que lembra a morfologia do $A$. necrophorus. Inoculações subcutâneas em coelhos determinam a morte em cêrca de uma semana e de alguns dêstes animais conseguimos cultura pura, seguindo a técnica de SCRIVNER e LeE (3) e já adotada por um de nós anteriormente (1). (fig. 3).

A cultura pura (figs. 4 e 5) obtida apresenta tôdas carateristicas, por nós pesquisadas, do A. necrophorus, e é altamente patogênica para o coelho. Não conseguimos imunização de coelhos por anacultura, embora tenhamos realizado poucas provas nesse sentido.

e) - Tratamento: o tratamento por nós indicado consistiu exclusivamente em lavagens diárias das zonas lesadas, com solução de permanganato de potássio a $0,25 \%$, antisséptico aconselhável principalmente nos processos infecciosos produzidos por anaeróbios. Embora o tratamento seja trabalhoso, o resultado foi nitidamente favorável e o animal se encontra, práticamente, curado, depois de 2 meses aproximadamente.

\section{RESUMO}

Os A.A. assinalam, pela primeira vez no Estado de São Paulo, uma forma clínica de necrobacilose em bezerro.

Relatam um caso, oriundo de um provável foco, do qual isolaram o Actinomyces necrophorus.

Obtiveram exito com o tratamento pelo permanganato de potássio a $0,25 \%$.

\section{SUMMARY}

The authors point out for the first time in the State of São Paulo (Brasil), a clinical form of necrobacillose in calf.

They report a case probably originated by a focus, from which they isolated the Actinomyces necrophorus.

They had success through a treatment of a $0,25 \%$ solution of potassium permanganate.

Ao Instituto Pinheiros nossos agradecimentos, por nos ter facilitado o material para exames bacteriológicos. 


\section{BIBLIOGRAFIA}

1 - Gióvine, N. - Rangel, N. - Machado, A. V. - Lamounier, R. D. Wilwerth, A. - 1943 - Necrobacilose (Súmula nosológica - A necrobacilose em Minas Gerais) Anais 2.0 Congresso Brasileiro Veterinária: $311-48$

2 - HAGAN, W. A. - 1943 - The infectious diseases of domestic animals. Ithaca, Comstock Publishing Company, Inc.

3 - Scrivner, L. H. - LeE, M. A. - 1934 - The morphology, culture, isolation and immunity studies of "Actinomyces necrophorus" in calf diphtheria. Jour. Amer. Vet. Med. Ass., 85: 360-78

\section{EXPLICAÇÃO DAS FIGURAS}

Fig. 1 - Necrobacilose: cabeça mostrando aumento de volume na região da apófise zigomática esquerda.

Fig. 2 - Necrobacilose: Lesão do casco.

Fig. $3-$ A. necrophorus: colônias em gelose-sôro.

Fig. 4-A. necrophorus: lâmina de colônia do tubo de gelose-sôro. Aumento: $90 \times 6$.

Fig. 5 - A. necrophorus: lâmina de cultura pura. Observar formas longas e curtas, granulosas. Aumento: $90 \times 4$. 
Romeu D. Lamounier e Paulo de Carva- Rev. Fac. Med. Vet. S. Paulo, Vol. 8, fase. 1-2 tho Pereira, Necrobacilose bovina

Estampa I

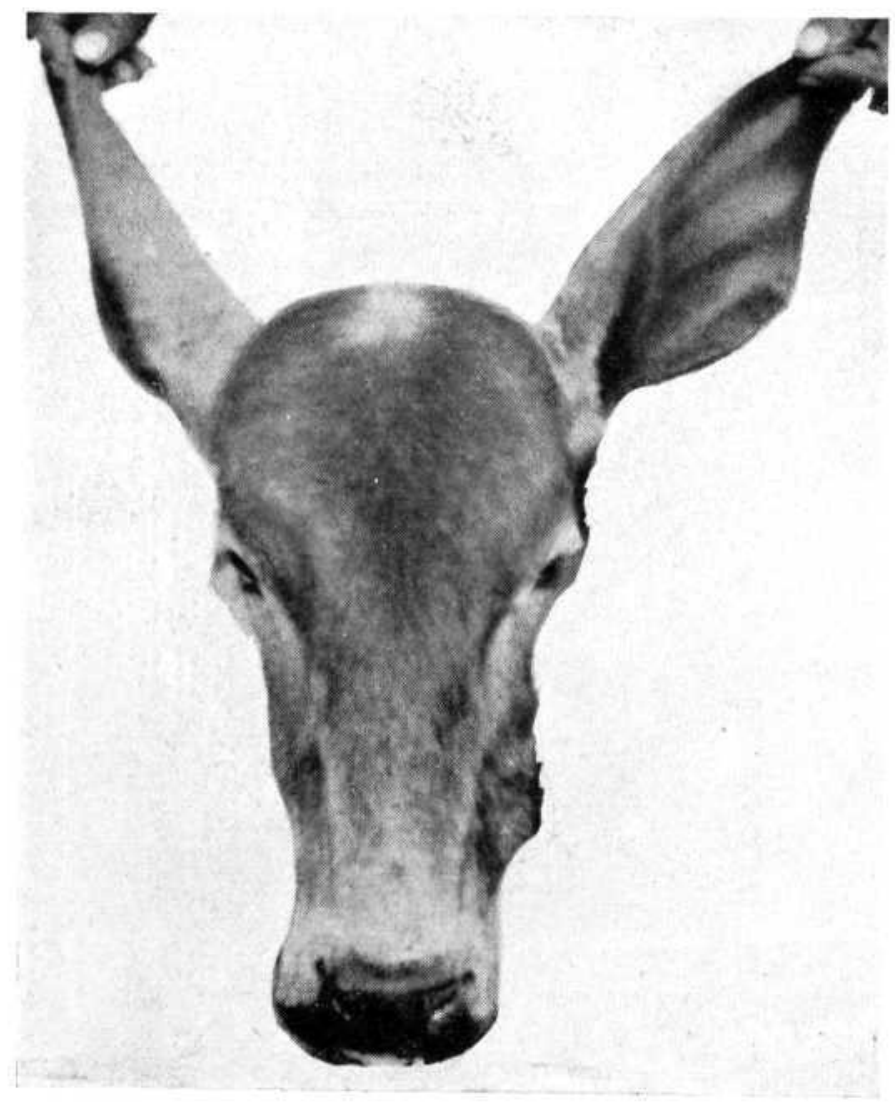

Fig. 1

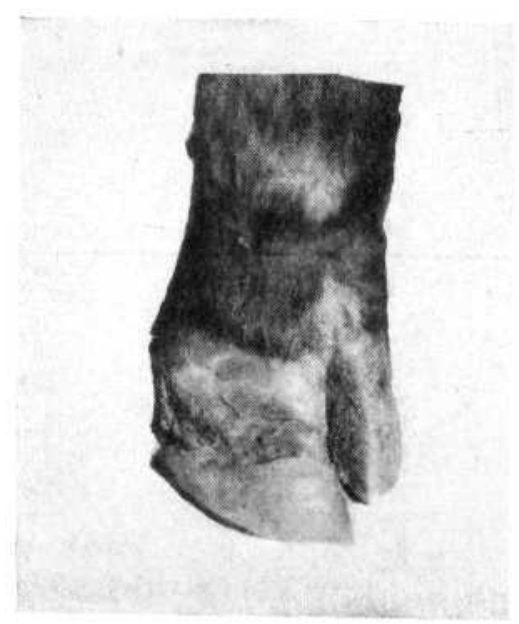

Fig. 2 
Romeu D. Lamounier e Paulo de Carvatho Pereira, Necrobacilose bovina
Rev. Fae. Med. Vet. S. Paulo, Vol. 3, fase, 1-2

Estampa II

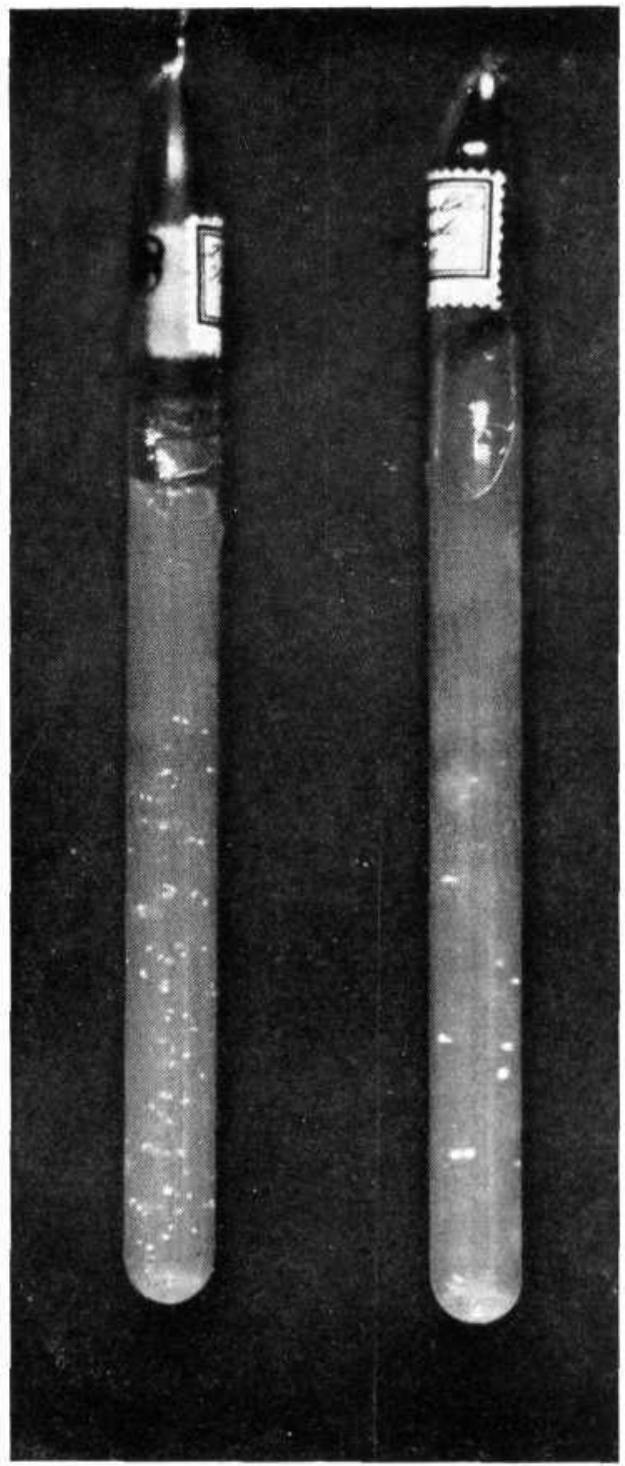

Fig. 3 
Romeu. D. Lamounier e Paulo de Carvatho Pereira, Necrobacilose bovina
Rev. Fac, Med. Vet. S. Paulo, Vol, 3, fasc. 1-2

Estampa III

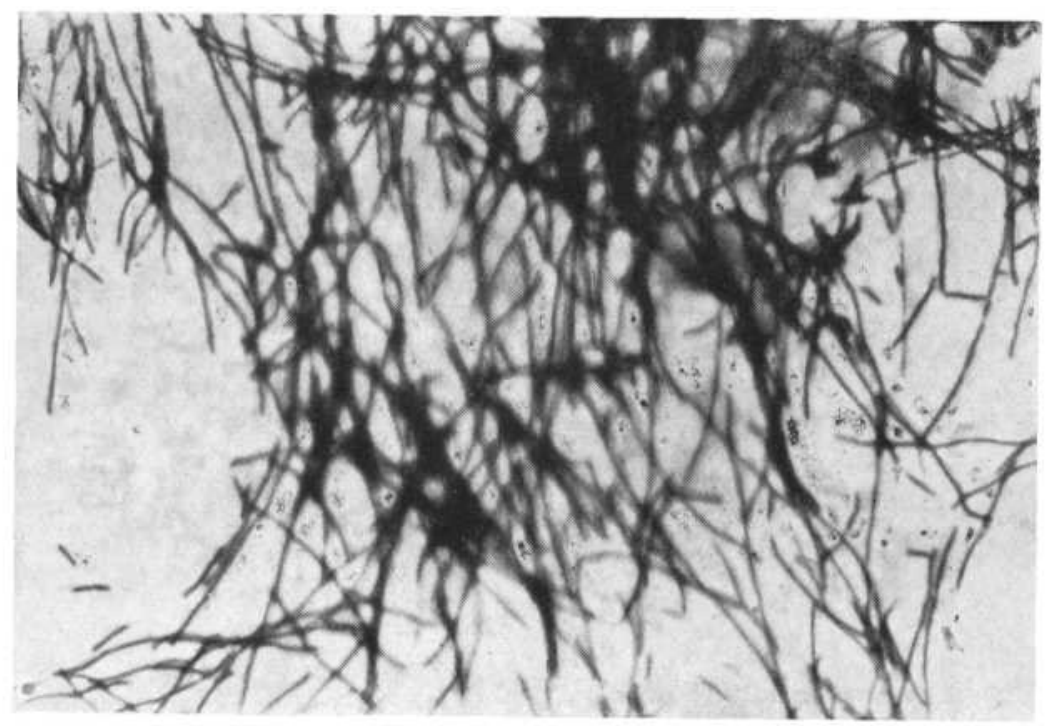

Fig. 4

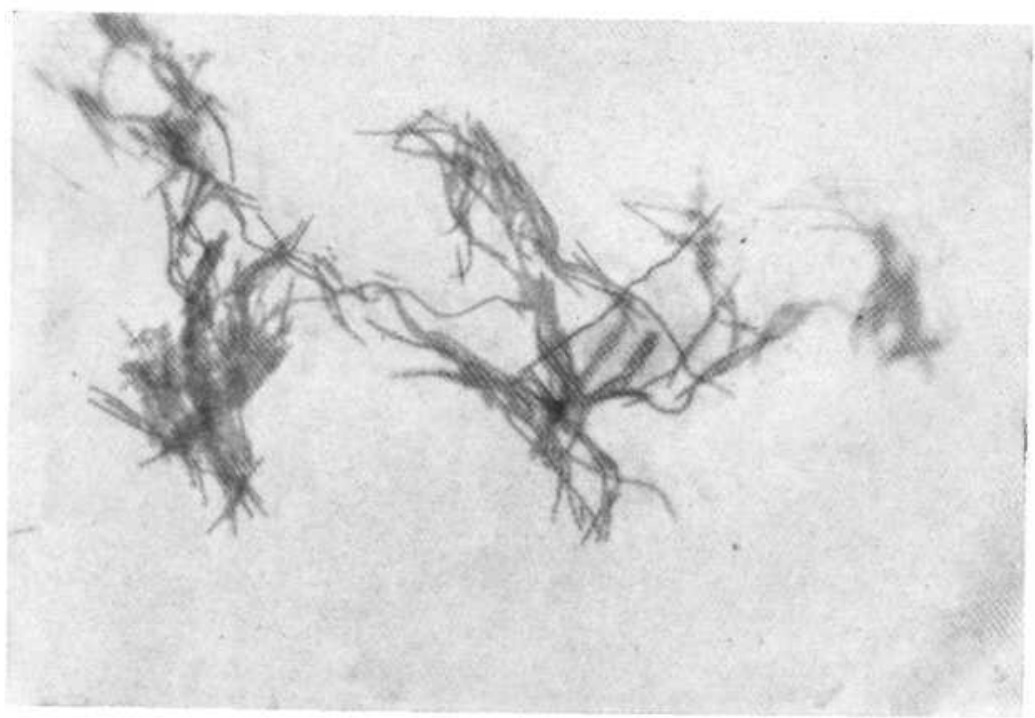

Fig. 5 